\title{
Depressive Response to Physostigmine Challenge in Borderline Personality Disorder Patients
}

\author{
Bonnie J. Steinberg, M.D., Robert Trestman, Ph.D., M.D., Vivian Mitropoulou, M.A., \\ Michael Serby, M.D., Jeremy Silverman, Ph.D., Emil Coccaro, M.D., Susan Weston, M.D., \\ Marie deVegvar, M.D., and Larry J. Siever, M.D.
}

The purpose of this study was to examine the relationship between mood and hormonal responses to cholinergic challenge with physostigmine in order to assess cholinergic system responsiveness in borderline personality disorder $(B P D)$ patients, other non-BPD personality disorder patients, and normal controls. Thirty-four personality disorder patients, 10 of whom met criteria for BPD and 24 of whom met criteria for other, non-borderline, personality disorders, and 11 normal controls participated in a double blind, placebo controlled physostigmine challenge paradigm. The Profile of Mood States depression subscale (POMS-D) self report measure was obtained at baseline and following the physostigmine or placebo infusions. A repeated measures ANOVA of POMS-D scores in placebo and drug conditions indicated a significantly greater depressive response in the total cohort of personality disorder patients than in the normal comparison group $(p<0.05)$. However, the depressive response to physostigmine was significantly greater in BPD patients, but not other personality disorder patients, compared to normal controls $(p<0.05)$. There was a correlation between the peak placebo-corrected depressive response to physostigmine and a group of $B P D$ traits related to affective instability but not a group of $B P D$ traits related to impulsivity. There was no correlation in any group between mood response to physostigmine and changes in plasma cortisol, prolactin, or growth hormone, or to nausea or other side effects following physostigmine infusion. These data suggest that there is an association between BPD and acute depressive responses to physostigmine challenge, and that the cholinergic system may be involved in the regulation of affect in Axis II disorders. [Neuropsychopharmacology 17:264-273, 1997] Published by Elsevier Science Inc.
KEY WORDS: Dysphoria; Affective instability; Cholinergic agents

While traditionally, psychodynamic and developmental models of borderline personality disorder (BPD) have been emphasized, there is an increasing apprecia-

From the Mt. Sinai School of Medicine and the Bronx VA Medical Center. Currently: Dr. Coccaro is at the Medical College of Pennsylvania, Philadelphia, PA; Dr. Weston is affiliated with the New York Hospital-Cornell Medical Center, New York, NY; and Dr. deVegvar is in private practice in Honolulu, HI.

Address correspondence to: Dr. L.J. Siever, M.D. The Bronx VA Medical Center, 116A, 130 West Kingsbridge Road, Bronx, NY 10468.

Received January 22, 1996; revised February 2, 1997; accepted February 18, 1997. tion of the biologic underpinnings of this disorder. Biologic correlates in this and other personality disorders are hypothesized to be associated with core psychobiologic vulnerabilities including impulsivity or affective instability, rather than one specific disorder (Siever and Davis 1991). Both of these traits have been found to have a familial (Zanarini et al. 1988; Silverman et al. 1991; Coccaro et al. 1994) and perhaps genetic (Torgersen $1984,1994)$ relationship with BPD. A number of studies have suggested that a hyporeactive serotonin system contributes to impulsivity in these patients. For example, patients with BPD have a blunted prolactin response to fenfluramine infusion associated with a history of suicidal behavior, and increased impulsivity or 
aggression (Coccaro et al. 1990). The reduced prolactin response to fenfluramine was significantly associated with the criteria of impulsivity, lack of control of anger and repeated self-damaging acts, but not any of the other criteria, including affective instability or unstable relationships (Siever and Trestman 1993).

Indeed, thus far there is no known biologic correlate of the affective instability of BPD. Affective instability is defined in DSM-IV as "intense episodic dysphoria, irritability, or anxiety usually lasting a few hours and only rarely more than a few days." These affective shifts often occur in response to environmental changes, especially in the interpersonal environment. The specific traits of BPD that are conceptually related to, and are empirically associated with, this hypersensitivity to environmental events include unstable relationships, identity disturbance, and chronic feelings of emptiness (Taylor and Goritsas 1994; Gardner and Cowdry 1986; Wickham and Reed 1987; Cowdry and Gardner 1988; Livesley and Schroeder 1991; Lewis and Harder 1990).

Previous formulations of BPD have emphasized the biological relationships between BPD and the mood disorders, including major depressive disorder (Siever et al. 1985; Gunderson and Elliott 1985), dysthymia, cyclothymia and bipolar disorder (Akiskal 1981), although the relationship between depression and BPD may not be as specific or salient as previously hypothesized. Furthermore, the character of the depressive episode in BPD may differ from more classical depressive episodes (Siever et al. 1985; Gunderson and Phillips 1991). Affective instability is a longstanding trait, or part of an enduring pattern of behavior, in contrast to the mood disorders, which are episodic and thus, would most likely be associated with a state-independent, or trait, biologic abnormality.

A logical starting point in a search for biological correlates of BPD would be to explore the correlates, primarily state-independent correlates, of the major affective disorders. As might be expected, state-dependent correlates of major depressive disorder, such as a blunted thyroid stimulating hormone response to thyroid releasing hormone and escape of plasma cortisol from the dexamethasone suppression test, are not consistently abnormal in borderline personality patients (Carroll et al. 1981; Siever et al. 1994).

There is a body of work implicating the cholinergic system, in part, in the pathophysiology of the mood disorders (Janowsky and Risch 1987; Janowsky and Overstreet 1995). This relationship appears to be state-independent, making the cholinergic system a candidate for studies of affective instability. Cholinomimetic drugs include both cholinesterase inhibitors physostigmine and diisopropylfluorophosphate, as well as direct muscarinic acetylcholine receptor agonists. These drugs produce dysphoria in depressed patients (Janowski and Risch 1987; Oppenheimer et al. 1979; Risch et al. 1983), manic patients (Davis et al. 1978; Janowski et al. 1974) and euthymic depressed patients (Oppenheimer et al. 1979); euthymic bipolar patients also have a depressive response to physostigmine in some (Rowntree et al. 1950), but not in all (Nurnberger et al. 1983) studies.

Cholinomimetic drugs have been found to reproduce depressive symptomatology in control subjects (Doerr and Berger 1983; Risch et al. 1981) in a dose dependent fashion (Fritze et al. 1988); although the depressive response is significantly less than in mood disorder patients (Risch et al. 1983). Symptoms have included depressive attitudes and passive, helpless strategies for coping with stress (Fritze et al. 1990) and behavioral inhibitory changes such as anergia, lethargy, decreased spontaneous activity, and diminished verbal fluency (Silva et al. 1992).

Cholinomimetics also produce changes in the hypothalamic-pituitary-adrenal axis similar to those seen in depression (elevations in corticotropin-releasing factor, ACTH, cortisol, and beta-endorphins), to a greater degree in mood disorder patients than controls even in the absence of nausea and vomiting (Janowsky and Risch 1984; Janowsky et al. 1982). Release of cortisol and prolactin have been hypothesized to be due, at least in part, to the stress effects of physostigmine infusion (Davis and Davis 1980). While growth hormone (GH) secretion by cholinomimetic infusion has been shown in rats (Janowsky and Risch 1984, 1987; Bruni and Meites 1978), it has been shown only inconsistently in humans (Davis and Davis 1980; Janowsky et al. 1981; O'Keane et al. 1992), and may be attenuated by administration of peripheral anticholinergic agents (Janowsky and Overstreet 1995); this response may also be due primarily to stress (Davis and Davis 1980). Thus, the measurement of hormone responses to cholinergic challenge allow an evaluation of the stressful effects of this challenge.

In a different paradigm, depressed patients (Sitaram et al. 1982), and borderline patients (Akiskal et al. 1985; McNamara et al. 1984), demonstrate characteristic changes in REM sleep, namely decreased latency and increased density. Cholinomimetics have been found to produce these changes in REM sleep in normal individuals (Gillin et al. 1991). Mood disorder patients (Sitaram et al. 1982; Jones et al. 1985) and, in a pilot study, BPD patients (Bell et al. 1983) showed a greater effect of cholinomimetics on REM latency and density than did cholinomimetics in normal controls.

These studies suggest that heightened responses to cholinomimetics may be a trait correlate of the mood disorders. BPD patients are characterized by hypersensitive depressive responses to environmental stimuli. Thus, it was hypothesized that this hypersensitivity, or affective instability, might also be partially mediated by cholinergic sensitivity. For this reason, a study using physostigmine, a cholinesterase inhibitor that increases cholinergic availability in the CNS, was undertaken to 
test the hypothesis that the cholinergic system contributes to the traits of BPD related to affective instability. We have compared a group of patients with BPD and a group of non-borderline personality disorder patients with a normal comparison group, in relation to affective instability and related traits, and to current or past episodes of major depression.

Primary hypotheses were 1) in response to physostigmine challenge, there would be a transient increase in depressive symptomatology, measured by mean placebo-corrected change (i.e., drug change-placebo change) in the depression subscale of the Profile of Mood States (POMS-D), which would be significantly higher in BPD patients, but not in other personality disorder patients, compared to the normal comparison group; and 2) the traits related to affective instability, but not those related to impulsivity and aggression, would be correlated with the placebo-corrected depressive response to physostigmine in personality disorder patients. Since the other personality disorder patients may have some BPD traits related to affective instability, they are hypothesized as having responses between the BPD and the comparison group, but not significantly different from either group. A secondary hypothesis was that current or past major depression in the personality disorder patients would not account for these findings, as affective instability was hypothesized to drive the association of BPD with cholinergic hyperresponsiveness.

\section{METHODS}

The sample consisted of 45 subjects who participated on two days in a randomized, double blind, placebo controlled study separated by $13.8 \pm 28.3$ days (mean \pm $\mathrm{SD})$; twenty-nine subjects received placebo first and 16 subjects received drug first.

We studied 34 personality disorder patients from the Mood and Personality Disorder Program at the Mount Sinai Medical Center and the Bronx VA Medical Centers. Each participant gave informed consent approved by the Internal Review Board. Ten $(5 \mathrm{M} / 5 \mathrm{~F})$ met criteria for BPD (age $33.6 \pm 7.9)$, and $24(15 \mathrm{M} / 9 \mathrm{~F})$ met criteria for at least one personality disorder other than $\mathrm{BPD}$ $(39.3 \pm 11.0)$ (Table 1). Eleven $(6 \mathrm{M} / 5 \mathrm{~F})$ normal controls (age $30.1 \pm 6.7$ ) were recruited by advertisement. None had a personal or family history of mood disorder or of personality disorder. All subjects were medically healthy, none had a history of substance dependence or intravenous drug abuse, and none had abused substances within six months. Subjects were medically screened with a history, physical examination, blood chemistries, complete blood count, thyroid function tests, urinalysis and urine toxicology screen, chest X-ray, and EKG. Medical information was approved by an internist not associ- ated with our program. All patients had negative breathalyzer tests during other procedures in our program. Patients with Bipolar I Disorder, Schizophrenia, other Axis I psychotic disorder, or Obsessive Compulsive Disorder were excluded. After complete description of the study to the subjects, written informed consent was obtained.

Diagnoses were established by one or more trained interviewers using the Schedule for Affective Disorders and Schizophrenia (SADS) (Spitzer and Endicott 1975) (revised for DSM-III-R) and the Structured Interview for the Diagnosis of Personality Disorders (SIDP) (Stangl et al. 1985) (interrater reliability $k=0.81$ ), for both DSM-III and DSM-III-R. A consensus was obtained in consultation with a clinical psychologist not otherwise involved in the study. The trait of affective instability was determined by the DSM-III BPD criterion five, affective instability: marked shifts from normal mood to depression, irritability, or anxiety, usually lasting a few hours and only rarely more than a few days, with a return to normal mood. In addition to criterion five, a group of traits related to affective instability empirically included DSM-III criteria two, four, and eight (unstable relationships, identity disturbance, chronic feelings of emptiness). Each criterion was rated in a three point scale 0-1 $(0=$ absent; $0.5=$ subthreshold; $1=$ present). During the protocol, mood was assessed by the Profile of Mood States (POMS), which measures global mood at a specific point in time; all subscales (depression, anxiety, anger, fatigue, vigor, confusion) were obtained (Table 2).

Subjects were studied in the Mount Sinai Clinical Research Center. All were medication free for at least two weeks, on a low monoamine diet for three days prior, and fasting past midnight the day of the protocol. Subjects were placed on bedrest and an intravenous catheter was inserted at $8 \mathrm{~A}$. M. At 9:30 A. M., to prevent cardiac side effects, glycopyrrolate, $0.2 \mathrm{mg}$ in $10 \mathrm{cc}$ normal saline, was administered intravenously over five minutes. At 10 A. M. physostigmine, $14 \mathrm{ug} / \mathrm{kg}$ in $10 \mathrm{cc}$ normal saline was given intravenously over 20 minutes. Side effects were rated on a scale of 0 to 3 , with 0 :no side effect, 1:dry mouth, 2:nausea, and 3:vomiting. The POMS was administered at $-60,+20$, and +75 minutes. Cortisol, prolactin and GH were drawn at $-5,-15,+20,+30$, +40 , and +80 minutes in relation to the infusion.

Plasma samples for cortisol, prolactin, and GH were collected in EDTA-treated tubes, kept on ice, centrifuged at $4^{\circ} \mathrm{C}$ and frozen at $-20^{\circ} \mathrm{C}$ within one hour. Plasma concentrations of $\mathrm{GH}$, prolactin, and cortisol were measured by radioimmunoassay using kit reagents obtained from ICN/Micromedic (Carson, CA). The assay for $\mathrm{GH}$ has an $\mathrm{ED}_{50}$ of $4.1 \mathrm{ng} / \mathrm{ml}$, a sensitivity of $0.5 \mathrm{ng} / \mathrm{ml}$, and inter- and intraassay coefficients of variation of $8 \%$ and $3 \%$, respectively. The assay for prolactin has an $\mathrm{ED}_{50}$ of $250 \mathrm{uIU} / \mathrm{ml}$, a sensitivity of $25 \mathrm{uIU} / \mathrm{ml}$, and inter- and intraassay coefficients of variation of $10 \%$ and $4 \%$, re- 
spectively. The assay for cortisol has an $\mathrm{ED}_{50}$ of $8.2 \mathrm{ug} \%$, a sensitivity of $0.5 \mathrm{ug} \%$, and inter- and intraassay coefficients of variation of $10 \%$ and $6 \%$, respectively.

A repeated measures analysis of variance using the change (peak minus baseline) in the POMS-D on the placebo day and the drug day as depended variables was conducted. Planned contrasts comparing the normal comparison group with a) the BPD group and b) the other personality disorder group, were performed as the primary analysis.

Pearson correlations (2-tailed) between both the placebo-corrected peak depressive response to physostigmine and both the traits of BPD related to hypersensitivity to environmental events (unstable relationships, identity disturbance, chronic feelings of emptiness and affective instability), and also the impulsive-aggressive
BPD traits (impulsivity, anger, self-damaging acts) were performed.

Several secondary analyses were performed to explore the relationships of responses to physostigmine with variables not hypothesized. A repeated measures ANOVA with gender, diagnosis and drug effect was performed. An analysis of covariance was performed to determine the effect of current or past major depression on depressive response to physostigmine. A repeated measures ANOVA was performed on the other subscales of the POMS (anxiety, anger, fatigue, vigor, and confusion) to evaluate baseline differences and changes from baseline after physostigmine; these measures were then Bonferroni corrected for the use of 5 scales in the exploratory analyses. Pearson correlations (2-tailed) between cortisol, prolactin, and $\mathrm{GH}$, and depressive response were

Table 1. Diagnoses and POMS Scores of Each Patient

\begin{tabular}{|c|c|c|c|c|c|c|}
\hline \multirow[b]{2}{*}{ Sex } & \multirow[b]{2}{*}{ Age } & \multirow[b]{2}{*}{ Diagnosis } & \multicolumn{2}{|c|}{ Placebo } & \multicolumn{2}{|c|}{ Drug } \\
\hline & & & Baseline & Response & Baseline & Response \\
\hline $\mathrm{F}$ & 39 & BPD, para, avoid & 23 & 9.00 & 25 & 7.00 \\
\hline $\mathrm{F}$ & 26 & $\mathrm{BPD}$, hist, narc & 16 & .00 & 10 & 13.00 \\
\hline $\mathrm{F}$ & 30 & BPD, hist & 12 & -4.00 & 7 & 7.00 \\
\hline $\mathrm{F}$ & 38 & BPD, hist, narc & 28 & 2.00 & 20 & 11.00 \\
\hline $\mathrm{F}$ & 29 & $\mathrm{BPD}$ & 7 & -1.00 & 7 & 38.00 \\
\hline M & 30 & BPD, hist, antisoc & 10 & -3.00 & 13 & -3.00 \\
\hline M & 52 & BPD, hist, antisoc & 21 & -5.00 & 17 & 1.00 \\
\hline M & 32 & BPD, comp & 21 & 5.00 & 32 & 1.00 \\
\hline M & 35 & BPD, para, schizt, hist, antisoc & 35 & -9.00 & 26 & 4.00 \\
\hline M & 25 & BPD, antisoc & 3 & -2.00 & 0 & .00 \\
\hline F & 23 & Mixed & 4 & 3.00 & 1 & 10.00 \\
\hline $\mathbf{F}$ & 39 & Mixed & 6 & -2.00 & 0 & .00 \\
\hline $\mathrm{F}$ & 36 & Hist & 19 & 14.00 & 17 & 4.00 \\
\hline $\mathrm{F}$ & 22 & Schizt & 0 & .00 & 2 & 3.00 \\
\hline $\mathrm{F}$ & 53 & Mixed & 39 & 8.00 & 28 & 10.00 \\
\hline $\mathrm{F}$ & 34 & Para, comp, hist & 0 & 1.00 & 4 & 6.00 \\
\hline $\mathrm{F}$ & 40 & Para, comp & 13 & .00 & 22 & 2.00 \\
\hline $\mathrm{F}$ & 40 & Hist & 7 & -4.00 & 6 & 14.00 \\
\hline $\mathrm{F}$ & 32 & Para, schizt & 0 & .00 & 0 & .00 \\
\hline M & 37 & Comp & 8 & -3.00 & 3 & .00 \\
\hline M & 51 & Comp & 0 & .00 & 0 & 14.00 \\
\hline M & 37 & Hist, avoid & 10 & 7.00 & 6 & 36.00 \\
\hline M & 62 & Schizoid & 41 & 2.00 & 43 & 8.00 \\
\hline M & 38 & Schizt & 8 & 2.00 & 35 & -2.00 \\
\hline M & 34 & Schizt & 1 & 1.00 & 6 & -5.00 \\
\hline M & 63 & Mixed & 19 & -7.00 & 0 & 3.00 \\
\hline M & 37 & Comp & 4 & -3.00 & 0 & 1.00 \\
\hline M & 34 & Schizt & 16 & -3.00 & 9 & 2.00 \\
\hline M & 28 & Hist & 5 & -1.00 & 5 & -1.00 \\
\hline M & 47 & Schizt & 2 & .00 & 2 & 11.00 \\
\hline M & 58 & Schizt, antisoc & 1 & -1.00 & 9 & -5.00 \\
\hline M & 32 & Antisoc & 9 & 3.00 & 9 & -2.00 \\
\hline M & 36 & Avoid & 0 & .00 & 0 & .00 \\
\hline M & 31 & Comp & 14 & 8.00 & 15 & 5.00 \\
\hline
\end{tabular}

Abbreviations: $\mathrm{BPD}=$ Borderline Personality Disorder, Para $=$ Paranoid Personality Disorder, Avoid = Avoidant Personality Disorder, Hist $=$ Histrionic Personality Disorder, Narc $=$ Narcissistic Personality Disorder, Antisoc $=$ Antisocial Personality Disorder, Comp $=$ Compulsive Personality Disorder, Schizt $=$ Schizotypal Personality Disorder, Mixed = Mixed Personality Disorder, Schizoid = Schizoid Personality Disorder. 
calculated. Demographic and clinical characteristics were evaluated by Student's $t$-test or $X^{2}$, as appropriate.

\section{RESULTS}

Table 1 lists each patient, age and gender, diagnoses, and POMS-D score at baseline and after challenge with placebo and physostigmine. A number of patients had multiple diagnoses, with the BPD group having an average of 2.8 personality disorder diagnoses, and the other personality disorder group having an average of 1.2 diagnoses $(t=4.96, d f=32, p<.0001)$. There was no difference between groups in gender distribution, or history of or current major depression (Table 3). There was no difference in age between the BPD group and

Table 2. Response Measures to Physostigmine (Mean \pm SD)

\begin{tabular}{|c|c|c|c|}
\hline & $\begin{array}{c}\text { Normal } \\
\text { Comparison }\end{array}$ & $\begin{array}{c}\text { Borderline } \\
\text { Personality } \\
\text { Disorder }\end{array}$ & $\begin{array}{c}\text { Other } \\
\text { Personality } \\
\text { Disorder }\end{array}$ \\
\hline Number of samples & 11 & 10 & 24 \\
\hline \multicolumn{4}{|l|}{ POMS-depression ${ }^{1}$} \\
\hline Placebo & $0.1 \pm 0.3$ & $-0.8 \pm 5.1$ & $1.0 \pm 4.5$ \\
\hline Drug & $0.2 \pm 0.6$ & $7.9 \pm 11.7$ & $4.7 \pm 8.5$ \\
\hline \multicolumn{4}{|l|}{ POMS-anxiety ${ }^{2}$} \\
\hline Placebo & $-0.6 \pm 1.5$ & $-1.0 \pm 4.0$ & $0.5 \pm 4.5$ \\
\hline Drug & $0.4 \pm 1.6$ & $6.0 \pm 7.7$ & $6.7 \pm 7.9$ \\
\hline \multicolumn{4}{|l|}{ POMS-anger $^{3}$} \\
\hline Placebo & $-0.1 \pm 0.6$ & $0.7 \pm 7.4$ & $1.6 \pm 5.6$ \\
\hline Drug & $0.0 \pm 0.5$ & $7.4 \pm 9.6$ & $3.5 \pm 6.6$ \\
\hline \multicolumn{4}{|l|}{ POMS-fatigue ${ }^{4}$} \\
\hline Placebo & $1.2 \pm 3.6$ & $0.6 \pm 5.3$ & $1.5 \pm 3.7$ \\
\hline Drug & $3.0 \pm 5.6$ & $4.3 \pm 8.0$ & $5.2 \pm 7.1$ \\
\hline \multicolumn{4}{|l|}{ POMS-vigor } \\
\hline Placebo & $-0.8 \pm 2.4$ & $0.9 \pm 5.1$ & $0.2 \pm 4.1$ \\
\hline Drug & $2.0 \pm 5.2$ & $3.2 \pm 6.8$ & $0.3 \pm 7.4$ \\
\hline \multicolumn{4}{|l|}{ POMS-confusion $^{5}$} \\
\hline Placebo & $0.0 \pm 0.3$ & $-0.2 \pm 2.2$ & $0.2 \pm 2.0$ \\
\hline Drug & $0.9 \pm 1.8$ & $4.3 \pm 4.2$ & $4.7 \pm 5.4$ \\
\hline \multicolumn{4}{|l|}{ Nausea $^{6}$} \\
\hline Placebo & $0.3 \pm 0.5$ & $0.4 \pm 0.5$ & $0.4 \pm 0.5$ \\
\hline Drug & $1.2 \pm 0.9$ & $1.5 \pm 0.5$ & $1.2 \pm 0.8$ \\
\hline Number of samples & 9 & 10 & 24 \\
\hline \multicolumn{4}{|l|}{ Plasma cortisol $^{7}$} \\
\hline Placebo & $3.8 \pm 6.2$ & $3.5 \pm 4.1$ & $2.8 \pm 4.6$ \\
\hline Drug & $8.7 \pm 7.3$ & $11.7 \pm 8.0$ & $11.5 \pm 9.5$ \\
\hline \multicolumn{4}{|l|}{ Plasma prolactin ${ }^{8}$} \\
\hline Placebo & $0.0 \pm 2.2$ & $-0.7 \pm 3.0$ & $-0.1 \pm 1.3$ \\
\hline Drug & $20.9 \pm 31.0$ & $21.3 \pm 29.0$ & $12.0 \pm 18.5$ \\
\hline \multicolumn{4}{|l|}{ Plasma $\mathrm{GH}^{9}$} \\
\hline Placebo & $-0.9 \pm 1.9$ & $-0.8 \pm 2.0$ & $-0.2 \pm 0.7$ \\
\hline Drug & $4.8 \pm 6.7$ & $1.5 \pm 7.7$ & $3.0 \pm 5.2$ \\
\hline
\end{tabular}

${ }^{1}$ Drug effect $(F[1,42]=9.39, p<.01) ; \operatorname{Dx} \times \operatorname{Drug}(F[1,42]=5.43, p<$ $0.03) \mathrm{BPD}>\mathrm{NC}$

${ }^{2-6}$ Drug effects $(F[1,42]>5.5, p<.03)$

${ }^{7}$ Drug effect $(F[1,39]=20.56, p<.01)$.

${ }^{8}$ Drug effect $(F[1,39]=19.46, p<.01)$.

${ }^{9}$ Drug effect $(F[1,39]=14.90, p<.01)$.
Table 3. Demographic and Clinical Characteristics of the Sample

\begin{tabular}{lccc}
\hline & $\begin{array}{c}\text { Normal } \\
\text { Comparison }\end{array}$ & $\begin{array}{c}\text { Borderline } \\
\text { Personality } \\
\text { Disorder }\end{array}$ & $\begin{array}{c}\text { Other } \\
\text { Personality } \\
\text { Disorder }\end{array}$ \\
\hline Number of samples & 11 & 10 & 24 \\
Sex & $6 \mathrm{M} / 5 \mathrm{~F}$ & $5 \mathrm{M} / 5 \mathrm{~F}$ & $15 \mathrm{M} / 9 \mathrm{~F}$ \\
Age (yrs $\pm \mathrm{SD})^{1}$ & $30.1 \pm 6.7$ & $33.6 \pm 7.9$ & $39.3 \pm 11.0$ \\
$\quad(\mathrm{M})$ & $29.1 \pm 5.3$ & $34.8 \pm 10.2$ & $41.6 \pm 11.5$ \\
$\quad(\mathrm{~F})$ & $31.4 \pm 8.6$ & $32.4 \pm 5.7$ & $35.4 \pm 9.4$ \\
Currently depressed & & $4(44.4 \%)$ & $7(29.2 \%)$ \\
Ever depressed & & $7(70 \%)$ & $17(70 \%)$ \\
Comorbid schizotypal & & $1(10 \%)$ & $7(29.2 \%)$ \\
Personality disorder & & $1(10 \%)$ & $6(25 \%)$ \\
Comorbid compulsive & & $6(60 \%)$ & $5(20.8 \%)$ \\
$\begin{array}{l}\text { Personality disorder } \\
\text { Comorbid histrionic }\end{array}$ & & &
\end{tabular}

${ }^{1} F[2,42]=3.8, p<.03, \mathrm{OPD}>\mathrm{NC}$.

the normal comparison group. There was, however, a difference in age with the other personality disorder group, but not the BPD group, being older than the normal comparison group (Table 3 ).

Table 4 lists the diagnoses and percentages of each personality disorder in both the BPD and the other personality disorder groups within the total sample. The $\mathrm{BPD}$ patients had an average of $5.7 \pm 0.9 \mathrm{BPD}$ traits, and the other personality disorder group had an average of $2.8 \pm 1.6$ BPD traits $(t=5.10, d f=32, p<.0001)$. Each member of the comparison group had no traits of BPD.

The time of the peak depressive response to physostigmine was different between patients and controls. Half of the patients experienced their peak depressive response to physostigmine at 20 minutes after the infu-

Table 4. Comorbid Personality Disorder Diagnoses

\begin{tabular}{llll}
\hline & Diagnosis & N & \% \\
\hline BPD Group & Histrionic & 6 & \\
& Antisocial & 4 & 40 \\
Narcissistic & 3 & 30 \\
Paranoid & 2 & 20 \\
Schizotypal & 1 & 10 \\
& Compulsive & 1 & 10 \\
Other PD Group & Avoidant & 1 & 10 \\
& & & \\
& Schizotypal & 7 & 29 \\
& Compulsive & 6 & 25 \\
& Histrionic & 5 & 21 \\
& Mixed & 4 & 16 \\
& Paranoid & 3 & 13 \\
& Antisocial & 2 & 8 \\
& Avoidant & 2 & 8 \\
& Schizoid & 1 & 4 \\
\hline
\end{tabular}




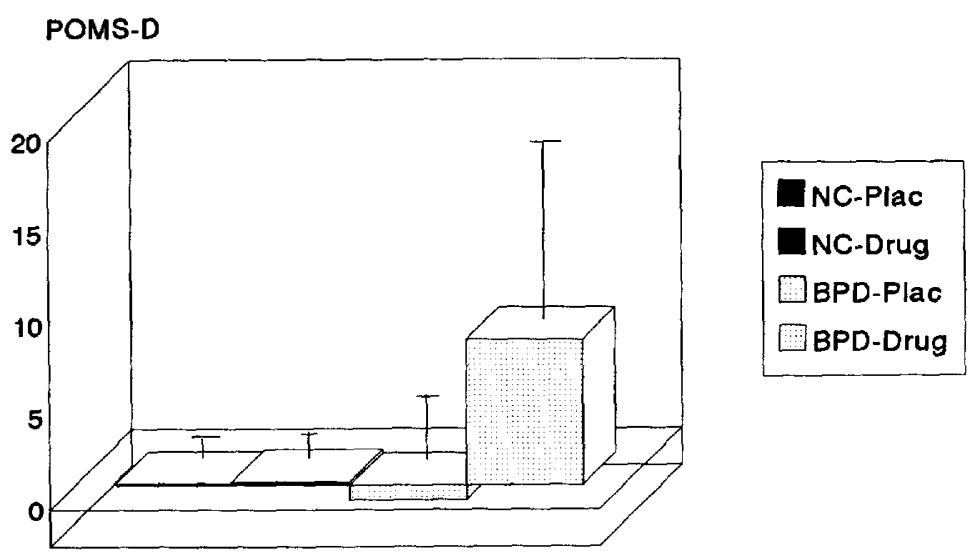

Figure 1. POMS-Depression Subscale Peak Response to Physostigmine and Plac in Borderline Patients and Normal Control Subjects. $\mathrm{N}=$ $21 ; F[1,42]=5.43 ; p<.03$ (mean $+\mathrm{SD}\}$. sion, and the other half at 75 minutes post infusion. In contrast $90 \%$ of the normal controls experienced their peak depressive response at 75 minutes post infusion $\left(X^{2}=6.6, d f=2, p<.03\right)$.

In a repeated measures ANOVA using planned contrasts there was an overall drug effect $(F[1,42]=9.39$, $p<.004)$, and a group by drug interaction, with the BPD patients having a significantly higher depression score compared to controls after the administration of the drug compared to placebo $(F[1,42]=5.43, p<.03)$, whereas the other personality disorder group was not significantly different from the normal comparison group $(F[1,42]=1.38, p=\mathrm{ns})$ (Figures 1,2). The results did not change when groups were age-matched.

If the BPD and the OPD groups are compared, they are not significantly different $(F[1,42]=1.4, p=n s)$. However, this categorical distinction between groups is determined by a diagnostic cutoff of five out of eight borderline traits, so that patients with three or four out of eight traits would be categorized in the OPD group, but would have substantial BPD symptomatology. If the personality disorder patients are interpreted as having a continuum of borderline traits ranging from 0 to 8 , the correlation between this continuum and the placebo-corrected depressive response to physostigmine is $r=0.30, n=34, p<.09$. The peak placebo-corrected de- pressive response to physostigmine correlated with the number of affective instability traits $(r=0.45, n=34$, $p<.01$ ), but not with the number of impulsive-aggressive traits ( $r=0.08, n=34, p=\mathrm{ns})$. Thus, the group of affective instability-related criteria (but not the impulsiverelated criteria) may account for the association between the diagnosis of borderline personality disorder and the increased placebo-corrected depressive response.

While borderline personality disorder was selected as a disorder characterized by its affective instability, other dramatic cluster personality disorders (i.e., histrionic, narcissistic, antisocial) share some affective instability characteristics. Another way of investigating that depressive response to physostigmine was not related to other traits (i.e., eccentricity or anxiety) we compared the depressive response of other non dramatic cluster personality disorders with prevalence of $20 \%$ or higher in our sample and the normal controls. This consisted of eight patients with schizotypal personality disorder and seven patients with compulsive personality disorder. No group by drug interaction was found regarding the depressive response between schizotypal subjects and normal controls $(F[1,17]=1.03, p=n s)$, or between compulsive subjects and normal controls $(F[1,16]=2.6$, $p=\mathrm{ns}$ ).

The placebo-corrected response to physostigmine on

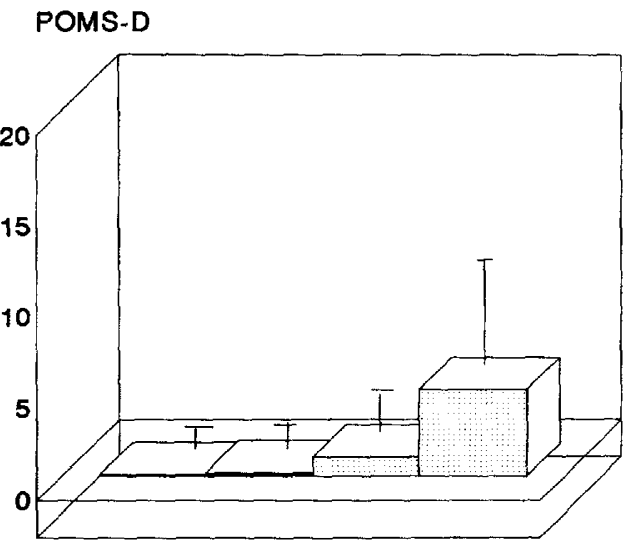

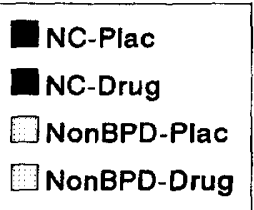

Figure 2. POMS-Depression Subscale Peak Response to Physostigmine and Plac in Non-Borderline Patients and Normal Control Subjects. $\mathrm{N}=35 ; F[1,42]=1.38 ; p=\mathrm{NS}$ (mean $+\mathrm{SD})$. 
the POMS depression subscale did not correlate with age or with the number of personality disorder diagnoses met, or with the number of days separating placebo and drug condition, and no order effects were observed.

Almost everyone (except two subjects) experienced modest nausea as an adverse effect (Table 2), and employing nausea on placebo and drug days as additional factors did not change the findings $(F[1,28]=4.91, p<$ $.04-\mathrm{BPD}>\mathrm{NC} ; F[1,28]=0.95, p=\mathrm{ns})$.

In order to address gender effects an exploratory two factor (gender, group membership) repeated measures ANOVA was conducted. Again, there was a significant group by drug interaction with BPD patients reporting higher depressive responses compared to the normal comparison group $(F[1,39]=5.53, p<.03)$. There was also a significant overall gender effect with women reporting higher levels of depressive response than men $(F[1,39]=6.03, p<.02)$, and a group by gender interaction with female BPD patients reporting higher levels of depressive response than the normal controls $(F[1,39]=$ $4.89, p<.03)$. In fact, female BPD patients reported the highest depressive response to physostigmine (15.2 \pm 13) of any group; however a gender by group by drug interaction was not statistically significant in this sample (Table 5).

After Bonferroni correction there were no differences between either the BPD or the other personality disorder group in baseline or peak measures on any of the other POMS subscales, nor was there a drug by group interaction with any of these measures.

There was no significant difference between mood response to physostigmine in the patients with current or past major depression as compared with either the normal controls or the other personality disorder patients; neither past nor present Major Depressive Disorder (MDD) in the personality disorder patients affected these results (Table 3 ).

Table 5. Response Measures to Physostigmine by Gender

\begin{tabular}{lccc}
\hline & $\begin{array}{c}\text { Normal } \\
\text { Comparison }\end{array}$ & $\begin{array}{c}\text { Borderline } \\
\text { Personality } \\
\text { Disorder }\end{array}$ & $\begin{array}{c}\text { Other } \\
\text { Personality } \\
\text { Disorder }\end{array}$ \\
\hline $\begin{array}{l}\text { POMS-depression } \\
\text { Number of samples }\end{array}$ & 11 & 10 & \\
(M/F) & $6 / 5$ & $5 / 5$ & $15 / 9$ \\
Placebo & $0.1 \pm 0.3$ & $-0.8 \pm 5.1$ & $1.0 \pm 4.5$ \\
M & $0.0 \pm 0.0$ & $-2.8 \pm 5.1$ & $0.3 \pm 3.8$ \\
F & $0.2 \pm 0.4$ & $1.2 \pm 4.8$ & $2.2 \pm 5.5$ \\
Drug & $0.2 \pm 0.6$ & $7.9 \pm 11.7$ & $4.7 \pm 8.5$ \\
M & $0.0 \pm 0.0$ & $0.6 \pm 2.5$ & $4.3 \pm 10.3$ \\
F & $0.4 \pm 0.8$ & $15.2 \pm 13.0$ & $5.4 \pm 4.9$ \\
\hline
\end{tabular}

Gender effect: $F[1,39]=6.03, p<.02$.

Drug effect: $F[1,39]=9.36, p<.01$.

Gender by group: $F[1,39]=4.89, p<.03$; female $\mathrm{BPD}>\mathrm{N} / \mathrm{C}$.

Group by drug: $F[1,39]=5.53, p<.03 ; \mathrm{BPD}>\mathrm{N} / \mathrm{C}$.
There was a drug effect, but no group by drug effect, of physostigmine on cortisol, prolactin and $\mathrm{GH}$, all of which increased after physostigmine. There was no correlation between depressive response to physostigmine and cortisol, prolactin or $\mathrm{GH}$ in response to physostigmine in either group (Table 2).

\section{DISCUSSION}

In this study the cholinesterase inhibitor physostigmine, which increases central availability of acetylcholine, was used as an index of hormonal and mood responsiveness in the cholinergic system. The placebocorrected depressive response to physostigmine was significantly higher in BPD patients than in the normal comparison group. This effect was found to be significant only for the depression subscale of the POMS, and this effect was not found in other personality disorder patients as compared with normal controls. Furthermore, neither past nor present MDD in the personality disorder patients affected these results.

The BPD traits related to affective instability together correlated with placebo-corrected depressive response to physostigmine. These traits (affective instability, unstable relationships, identity disturbance and chronic feelings of emptiness) may be conceptualized as forming a group of related symptoms, in a variety of spheres, which are due to, or reactions to, a proclivity to depressive response (Taylor and Goritsas 1994). Moreover, the other personality disorder group (i.e., the nonborderline personality group) (see Table 1) that was utilized as a psychiatric comparison group may have some borderline traits (though they do not meet criteria for the disorder). Indeed, affective instability related traits, and not impulsivity traits correlate significantly with the placebo corrected depressive response to physostigmine suggesting that affective instability traits may account for the group differences. In this case, it is not surprising that the other personality disorder patients with these traits may also exhibit modest depressive responses to physostigmine, supporting a dimensional, rather than categorical, model of the relationship between biologic systems and personality disorder traits, such as impulsivity or affective instability.

Other studies have similarly found that affective instability traits cluster together in factor analysis of BPD traits, as contrasted to symptoms related to impulsivity (Livesley and Schroeder 1991; Lewis and Harder 1990). In addition, a number of studies has shown that response to medication of impulsive traits is not correlated with a response to affective traits (Gardner and Cowdry 1986; Wickham and Reed 1987; Cowdry and Gardner 1988). Notably, the impulsive-aggressive traits, including impulsivity, anger, and self-damaging acts, do 
not correlate with depressive response to physostigmine. These traits may correlate more closely to serotonergic, or possibly even noradrenergic, measures (Siever and Davis 1991; Coccaro et al. 1990; Siever et al. 1994).

In another study from our laboratory, we administered a visual analog scale of mood with drug challenge by fenfluramine, to which the BPD patients had a trend toward a placebo-corrected euphoric response (Siever et al., unpublished data). There was no mood response to drug challenge by clonidine (Siever et al., unpublished data). This suggests that the depressive response in BPD patients to cholinergic challenge is not a nonspecific depressive response to a challenge study, but rather a more specific response to cholinergic challenge.

There are some limitations to the methodology of this study. While the peripheral cholinergic agent was administered on both days, the placebo itself was inactive, so that nausea or any discomfort was greater on the days of the physostigmine infusion, possibly confounding the blind as well. However, the lack of group, or group by drug, effect of the physostigmine infusion on $\mathrm{GH}$, cortisol, or prolactin, and the lack of their correlation with the depressive response, make it unlikely that the differential depressive responses to physostigmine are due merely to a stress response or to the discomfort of physostigmine infusion. In addition, the drug induced mild to moderate nausea almost universally in our subjects, and the degree of nausea does not account for the differences found.

While there was a gender effect and a group by gender interaction, there was no gender by drug interaction and therefore no three-way interaction. However, while not significant, female BPD patients reported a higher depressive response to physostigmine than any other group. It may be that this difference was not significant because the sample size in each group did not provide the necessary power to detect a gender by drug by group effect in this sample. It has been shown that the rat forebrain cholinergic system is sensitive to activational and organizational effects of gonadal hormones, with induction of choline acetyltransferase mediated by estradiol (McEwen et al. 1991). Differences in sensitivity in females in response to physostigmine might, if detected in larger samples, be indicative either of differences in the cholinergic systems of males and females, or of a more exquisite sensitivity in women to increased central cholinergic environment. Future studies would be required to address this issue directly.

In this initial study, which calls for further investigation, we have found that patients with BPD have a depressive response to physostigmine. This finding is most robust in the female BPD patients and appears to be specific to cholinergic challenge. A group of traits related to hypersensitivity to environmental events, which includes affective instability, unstable relationships, identity disturbance and chronic feelings of emptiness, may account for the depressive response to physostigmine, as they correlate with this response, whereas the impulsiveaggressive traits of BPD do not. It may, thus, be that in patients with borderline personality disorder the affective instability is mediated, at least in part, by the cholinergic system or by cholinergic supersensitivity; and that differences in other neurotransmitter systems, such as the serotonergic and the noradrenergic systems, influence the expression of cholinergic supersensitivity in different ways in the Axis I and Axis II disorders.

\section{ACKNOWLEDGMENTS}

This research is supported in part by grants from the National Institute of Health; the National Center for Research Resources for Mt. Sinai Clinical Research Center (RR00071); the National Institute of Mental Health, for Mt. Sinai Clinical Research Center (R01-NH41131); the Department of Veterans Affairs Merit Award (7609004) and the Department of Veterans Affairs Young Psychiatry Research Traineeship. The authors wish to acknowledge the work of Virginia Condello, M.D., Julia Temple, M.D., Irene Lopez, B.A., Damon Mitchell, B.A., and Philip Lehrman, B.A. We would like to acknowledge the support and helpful suggestions of Kenneth L. Davis, M.D.

\section{REFERENCES}

Akiskal HS (1981): Subaffective disorders: dysthymic, cyclothymic and bipolar II disorders in the "borderline" realm. Psychiatr Clin North Am 4:25-46

Akiskal HS, Yerevarian BI, Davis GC, King D, Lemmi H (1985): The nosologic status of borderline personality: clinical and polysomnographic study. Am J Psychiatry 142:192-198

Bell J, Lycaki H, Jones D, Kelwala S, Sitaram N (1983): Effect of preexisting borderline personality disorder on clinical and EEG sleep correlates of depression. Psychiatry Res 9:115-123

Bruni JF, Meites J (1978): Effects of cholinergic drugs on growth hormone release. Life Sci 23:1351-1358

Carroll BJ, Greden JF, Feinberg M, Lohr N, Norman JM, Steiner M, Haskett RF, Albala AA, deVigne JP, Tarika J (1981): Neuroendocrine evaluation of depression in borderline patients. Psychiatr Clin North Am 4:89-99

Coccaro EF, Siever LJ, Klar HM, Maurer G, Cochrane K, Cooper TB, Mohs RC, Davis KL (1989): Serotonergic studies in patients with affective and personality disorders: correlates with suicidal and impulsive aggressive behavior. Arch Gen Psychiatry 46:587-599 (correction, 1990; 47:124)

Coccaro EF, Silverman JM, Klar HM, Horvath TB, Siever LJ (1994): Familial correlates of reduced central serotonergic system function in patients with personality disorders. Arch Gen Psychiatry 51:318-324

Cowdry RW, Gardner PL (1988): Pharmacotherapy of borderline personality disorder: alprazolam, carbamazepine, trifluoperazine, tranylcypromine. Arch Gen Psychiatry 45:111-119 
Davis KL, Berger PA, Hollister LE, Defraites E (1978): Physostigmine in mania. Arch Gen Psychiatry 35:119-122

Davis BM, Davis KL (1980): Cholinergic mechanisms and anterior pituitary hormone secretion. Biol Psychiatry 15: 303-310

Doerr P, Berger M (1983): Physostigmine-induced escape from dexamethasone suppression in normal adults. Biol Psychiatry 18:261-268

Fritze J, Sofic E, Riederer P, Beckmann H (1988): Endocrine parameters and biogenic amines in relationship to psychopathology after cholinergic drug challenge (RS 86). Psychiatry Res 25:339-348

Fritze J, Sofic E, Muller T, Pfuller $\mathrm{H}$, Lanczik M, Riederer $\mathrm{P}$ (1990): Cholinergic-adrenergic balance: Part 2, relationship between drug sensitivity and personality. Psychiatry Res 34:271-279

Gardner DL, Cowdry RW (1986): Positive effects of carbamazepine on behavioral dyscontrol in borderline personality disorder. Am J Psychiatry 143:519-522

Gillin JC, Sutton L, Ruiz C. Kelose J. Dupont RM, Darko D, Risch SC, Golshan S, Janowsky DS (1991): The cholinergic rapid eye movement induction test with arecoline in depression. Arch Gen Psychiatry 48:264-270

Gunderson JG, Elliott GR (1985): The interface between borderline personality and affective disorder. Am J Psychiatry 142:277-288

Gunderson JG, Phillips KA (1991): A current view of the interface between borderline personality disorder and depression. Am J Psychiatry 148:967-975

Janowsky DS, El-Yousef MK, Davis JM (1974): Acetylcholine and depression. Psychosom Med 36:248-257

Janowsky DS, Risch SC, Judd LL, Huey LY, Parker DC (1981): Cholinergic supersensitivity in affect disorder patients: behavioral and neuroendocrine observations. Psychopharm Bull 17:129-132

Janowsky DS, Risch SC (1987): The role of acetylcholine mechanisms in the affective disorders. In Meltzer HY (ed), Psychopharmacology: The Third Generation of Progress. New York, Raven Press

Janowsky DS, Risch SC, Parker DC, Huey LY, Judd LL (1982): Behavioral-neuroendocrine effects of physostigmine. In Proceedings of the 13th Collegium Internationale NeuroPsychopharmacologicum Congress, Jerusalem, Israel (abstract), June 1982

Janowsky DS, Risch SC (1984): Cholinomimetic and anticholinergic drugs used to investigate an acetylcholine hypothesis of affective disorder and stress. Drug Dev Res 4:125-142

Janowsky DS, Overstreet D (1995): Acetylcholine in affective disorders. In Bloom FE, Kupfer DJ, Psychopharmacology: The Fourth Generation of Progress. New York, Raven Press

Jones D, Kalwala S, Bell J, Dube S, Jackson E, Sitaram N (1985): Cholinergic REM response: correlation with major depressive subtype. Psychiatry Res 14:99-110

Lewis SJ, Harder DW (1990): Factor structure of the MCMI among personality disordered outpatients and in other populations. J Clin Psychology 46:613-617

Livesley WJ, Schroeder ML (1991): Dimensions of personal- ity disorder: the DSM-III-R cluster B diagnoses. J Nerv Ment Dis 179:320-328

McEwen BS, Coirini H, Westlind-Danielsson A, Frankfurt M, Gould E, Schumacher M, Woolley C (1991): Steroid hormones as mediators of neural plasticity. J Steroid Biochem Mol Biol 39:223-232

McNair DM, Lorr M, Droppleman LF (1971): Profile of Mood States, Educational and Industrial Testing Service, San Diego

McNamara I, Reynolds CF III, Soloff PH, Mathias R, Rossi A, Spiker D, Coble PA, Kupfer DJ (1984): EEG sleep evaluation of depression in borderline patients. Am J Psychiatry 141:182-186

Nurnberger JI, Jimerson DC, Simmons-Alling S, Tamminga C, Nada NS, Lawrence D, Sitaram N, Gillin IC, Gershon ES (1983): Behavioral, physiological, and neuroendocrine responses to arecoline in normal twins and "well state" bipolar patients. Psychiatry Res 9:1.91-200

O'Keane V, O'Flynn K, Lucey J, Dinan TG (1982): Pyridostigmine-induced growth hormone responses in healthy and depressed subjects-Evidence for cholinergic supersensitivity in depression. Psychol Med 22:55-60

Oppenheimer G, Ebstein R, Belmaker R (1979): Effect of lithium on the physostigmine induced behavioral syndrome and plasma cyclic GMP. J Psychiatric Res 15:133-138

Risch SC, Janowsky DS, Gillin JC (1981): Muscarinic supersensitivity of anterior pituitary ACTH and beta endorphin release in major depressive illness. Peptides 9:789-792

Risch SC, Siever LJ, Gillin JC, Janowsky D, Sitaram N, Weker J, Cohen RM, Murphy DL (1983): Differential mood effects of arecoline in depressed patients and normal volunteers. Psychopharmacol Bull 19:696-698

Rowntree DW, Neven S, Wilson A (1950): The effect of diisopropylfluorophosphonate in schizophrenia and manic depressive psychosis. J Neurol Neurosurg Psychiatry 13:47-62

Siever LJ, Davis KL (1991): A psychobiological perspective on the personality disorders. Am J Psychiatry 148:1647-1658

Siever LJ, Klar H, Coccaro EF (1985): Psychobiologic substrates of personality. In Biologic Response Styles: Clinical Implications. Klar H, Siever LJ (eds), American Psychiatric Press, Washington, DC

Siever LJ, Steinberg BJ, Trestman RL, Intrator J (1994): Personality disorders: biological markers. In Oldham JM, Riba MB, Review of Psychiatry, Vol 13., Washington, DC, American Psychiatric Press

Siever L, Trestman RL (1993): The serotonin system and aggressive personality disorder. Int Clin Psychopharmacol 8 (suppl 2):33-39

Silva SG, Stern RA, Colder RN, Davidson EJ, Janowsky DS: The effects of physostigmine on behavioral inhibition, cognition and mood in healthy males. Presented at Society of Biological Psychiatry Annual Meeting 1992, and American Psychological Association Annual Meeting, 1992

Silverman JM, Pinkham L, Horvath TB, Coccaro EF, Klar H, Schear S, Apter S, Davidson M, Mohs RC, Siever LJ (1996): Affective and impulsive personality disorder traits in the relatives of patients with borderline personality disorder. Am J Psychiatry 148:1378-1385

Sitaram N, Nurnberger J, Gershon ES, Gillin JC (1982): Cho- 
linergic regulation of mood and REM sleep: a potential model and marker for vulnerability to depression. Am J Psychiatry 139:571-576

Spitzer RL, Endicott J (1975): The Schedule for Affective Disorders and Schizophrenia (SADS), New York Biometrics Research, N.Y. State Psychiatric Institute

Stangl D, Pfohl B, Zimmerman M, Bowers W, Corenthal C (1985): Structured interview for the DSM-III personality disorders. Arch Gen Psychiatry 42:591-596

Taylor S, Goritsas E (1994): Dimensions of identity diffusion. J Pers Disord 8:229-239
Torgersen S (1984): Genetic and nosologic aspects of schizotypal and borderline personality disorders: a twin study. Arch Gen Psychiatry 41:546-554

Torgersen S (1994): Genetics in borderline conditions. Acta Psychiatr Scand Suppl 379:19-25

Wickham EA, Reed JV (1987): Lithium for the control of aggressive and self-mutilating behavior. Int Clin Psychopharmacology 2:181-190

Zanarini MC, Gunderson JG, Marino MF, Schwartz EO, Frankenburg FR (1988): DSM-III disorders in the families of borderline outpatients. J Pers Disord 2:292-302 